\title{
Pengujian Kolimator Pada Pesawat Sinar-X Mobile Unit Merek Siemens Di Instalasi Radiologi RSUD K.R.M.T Wongsonegoro Semarang
}

\section{Collimator Testing On Siemens X-Ray Mobile Unit At Radiology Installations K.R.M.T Wongsonegoro Semarang General Hospital}

Kesawa Sudarsih, Nanik Suraningsih, Mega Indah Puspita

\section{Intisari}

Program kendali mutu mencakup beberapa pengujian, termasuk pengujian kolimator. Menurut Kepmenkes No.1250 Tahun 2009, pengujian kolimator dilakukan sebulan sekali atau setelah perbaikan. Instalasi Radiologi RSUD K.R.M.T Wongsonegoro Semarang, saat dilakukan pemeriksaan baby gram dan thoraks menggunakan pesawat Sinar- $X$ mobile unit dengan pengaturan luas lapangan sesuai ukuran objek, ternyata hasil radiograf yang dihasilkan terpotong. Pesawat Sinar-X ini digunakan pada tahun 2006. Selama digunakan belum pernah dilakukan pengujian kolimator. Penelitian ini bertujuan untuk mengetahui hasil kesesuaian berkas cahaya kolimator.

Jenis penelitian ini adalah penelitian kuantitatif dengan pendekatan observasional. Penelitian ini menggunakan alat Collimator Test Tool dengan variasi FFD $100 \mathrm{~cm}$ dan $150 \mathrm{~cm}$, luas lapangan penyinaran diatur $14 \times 18 \mathrm{~cm}$. Hasil pengujian ditabulasi, kemudian dianalisis berdasarkan Kepmenkes No.1250 tahun 2009. Batas toleransi nilai pergeseran $\leq 2 \%$ dari FFD yang digunakan.

Hasil pengujian kolimator menunjukkan bahwa pada $F F D ~ 100 \mathrm{~cm}$ diperoleh rata-rata sumbu $X=1,38 \%$, sumbu $Y=1,5 \%$. FFD $150 \mathrm{~cm}$ diperoleh rata-rata sumbu $X=1,73 \%$, sumbu $Y=1,42 \%$. Nilai pergeseran yang terjadi masih dalam batas toleransi. Sebaiknya dilakukan pengujian secara berkala satu bulan sekali untuk menjamin mutu radiografi.

Kata kunci: Kendali mutu, pengujian kolimator, collimator test tool, RSUD K.R.M.T Wongsonegoro Semarang

Afiliasi Penulis

Prodi D3 Teknik Rontgen STIKES Widya Husada Semarang

Korespondensi kepada

K. Sudarsih

kekeyragil@gmail.com 


\section{Abstract}

The quality control program includes several tests, including collimator testing. According to Kepmenkes No.1250 Year 2009, collimator testing is done once a month or after repair. Radiology Installation RSUD K.R.M.T Wongsonegoro Semarang, when examined baby gram and thoraks using aircraft X-ray mobile unit with wide field settings according to object size, the result of the resulting radiograph cut off. This X-ray plane was used in 2006. During the use, no collimator testing has been performed. This study aims to determine the results of the suitability of light beam collimator.

His type of research is quantitative research with observational approach. This research uses Collimator Test Tool tool with variation of FFD $100 \mathrm{~cm}$ and $150 \mathrm{~cm}$, the field of irradiation is set $14 \times 18 \mathrm{~cm}$. The test results were tabulated, then analyzed based on Kepmenkes No.1250 in 2009. Limit tolerance value of shift $\leq 2 \%$ of FFD used.

The result of collimator test shows that in FFD $100 \mathrm{~cm}$ we get the average $X$ axis $=1.38 \%, Y$ axis $=1.5 \%$. FFD $150 \mathrm{~cm}$ obtained average $X$ axis $=1.73 \%, Y$ axis $=1.42 \%$. The value of the shift that occurs is still within the limits of tolerance. We recommend that you do a periodical test once a month to ensure the quality of radiography.

Keywords: Quality control, collimator testing, collimator test tool, RSUD K.R.M.T Wongsonegoro Semarang

\section{Pendahuluan}

Progam kendali mutu merupakan salah satu progam jaminan mutu yang bertujuan untuk melakukan monitoring dan perawatan yang bersifat teknis agar tidak mengurangi gambaran kualitas yang dihasilkan. Selain itu, program kendali mutu merupakan bagian dari progam jaminan mutu yang berhubungan dengan instrumentasi atau pemakaian pesawat dan peralatan (Papp, 2011). Salah satu pengujian dalam kendali mutu radiologi adalah uji kesesuaian kolimator. Kolimator berbentuk kotak dan berfungsi sebagai pembatas Sinar-X yang keluar (Puspitasari, 2010).

Pengujian terhadap kolimator perlu dilakukan untuk mengetahui kesesuaian berkas kolimator dengan arah berkas sinar-X. Kolimator merupakan salah satu parameter utama yang harus dilakukan uji kesesuaian. Maksud dari parameter utama uji kesesuaian adalah parameter yang secara langsung mempengaruhi dosis radiasi pasien dan kualitas citra yang dihasilkan (Bapeten, 2011).

Pada pengujian kolimator ini ada beberapa metode yaitu metode kawat "L", metode koin, dan metode Collimator Test Tool. Menurut Kemenkes No. 1250 Tahun 2009 tentang Pedoman Kendali Mutu batas pergeseran kolimator adalah $\leq 2 \%$ dari FFD (Focus Film Distance). Frekuensi pengujian kolimator adalah satu bulan sekali atau setelah perbaikan kolimator dan satu bulan sekali apabila pencahayaan kolimator berkurang.

Berdasarkan observasi di Instalasi Radiologi RSUD K.R.M.T Wongsonegoro Semarang, untuk pemeriksaan babygram di ruang perinatologi dan di ruang ICU untuk proyeksi thoraks, dilakukan menggunakan pesawat Sinar- $\mathrm{X}$ mobile unit merek Siemens. Dalam melakukan pemotretan baby gram dan thoraks pengaturan kolimator menggunakan luas lapangan yang lebar, tidak sesuai dengan ukuran objek yang diperiksa.Pada saat pemotretan baby gram dan thoraks pengaturan luas lapangan sesuai ukuran objek, ternyata hasil radiograf terpotong sehingga terjadi pengulangan radiograf. Pesawat ini dipasang dan digunakan pada tahun 2006 selama digunakan pesawat tersebut belum pernah dilakukan pengujian kolimator sampai sekarang. Kondisi shutter pada kolimator tersebut kurang baik saat dilakukan penutupan sehingga terjadi ketidaksejajaran pada kolimator atau tidak simetris antara kanan dan kiri sehingga saat melakukan pemotretan harus dibuka selebarlebarnya. Hal ini dimungkinkan disebabkan karena ketidaksesuaian antara luas lapangan kolimator dengan berkas Sinar-X yang dihasilkan.

Dari latar belakang tersebut, penulis tertarik untuk melakukan penelitian dengan judul 
"Pengujian Kolimator pada Pesawat Sinar-X Mobile Unit Merek Siemens di Instalasi Radiologi RSUD K.R.M.T Wongsonegoro Semarang".

\section{Metode}

Jenis penelitian ini adalah penelitian kuantitatif dengan pendekatan observasional. Penelitian ini dilakukan di Instalasi Radiologi RSUD K.R.M.T Wongsonegoro Semarang pada bulan Juni 2017. Pengumpulan data dilakukan dengan cara melakukan pengamatan, pengujian, dan dokumentasi. Pengujian menggunakan alat collimator test tool dengan luas lapangan yang digunakan adalah ukuran $14 \times 18 \mathrm{~cm}$ dengan variasi FFD $100 \mathrm{~cm}$ dan $150 \mathrm{~cm}$. Hasil pengujian berupa radiograf yang kemudian diukur nilai pergeseran dalam sajian tabel. Kemudian hasil dianalisis berdasarkan Kepmenkes No.1250 tahun 2009 yaitu batas toleransi nilai pergeseran $\leq 2 \%$ dari FFD yang digunakan.

\section{Hasil \& Pembahasan}

Prosedur Pengujian kolimator Menggunakan Metode Collimator Test Tool pada Pesawat Sinar-X Mobile Unit Merek Siemens di Instalasi

\section{Radiologi K.R.M.T Wongsonegoro Semarang}

Prosedur pengujian kolimator dengan metode Collimator Test Tool pada pesawat sinar-X mobile unit merek Siemens dilakukan dengan cara yaitu: Menghidupkan Pesawat Sinar- $X$ mobile unit merek Siemens beserta CR (Computed Radiography). Tunggu beberapa saat setelah pesawat "ON" agar pesawat dalam kondisi siap digunakan. Mensejajarkan tabung Sinar- $X$ di atas meja pemeriksaan dengan meletakkan waterpass di atas tabung Sinar$\mathrm{X}$. Mensejajarkan cahaya kolimator di atas meja pemeriksaan dengan cara meletakkan waterpass di atas kolimator. Mensejajarkan meja pemeriksaan dengan cara meletakkan waterpass di atas meja pemeriksaan. Meletakkan imaging plate dengan ukuran $35 \times 35 \mathrm{~cm} \mathrm{~cm}$ di atas meja pemeriksaan. Mengatur FFD setinggi $100 \mathrm{~cm}$ dan $150 \mathrm{~cm}$. Meletakkan Collimator Test Tool di atas kaset $35 \times 35 \mathrm{~cm}$ yang telah disiapkan. Mengatur Luas cahaya kolimator seluas persegi pada luas bidang Collimator Test Tool dengan dimensi $14 \times 18 \mathrm{~cm}$. Mengatur Faktor eksposi $44 \mathrm{kV}$, dan 5 mAs pada
FFD $100 \mathrm{~cm}$ dan FFD $150 \mathrm{~cm}$. Pengaturan tersebut untuk pengujian eksposi pertama, kedua dan ketiga. Kemudian melakukan prosesing menggunakan Computed Radiography.

\section{Hasil Pengujian Kolimator}

Hasil pengujian kolimator dengan metode Collimator Test Tool pada pesawat sinar-X mobile unit merek Siemens dapat dilihat pada gambar 1.

Setelah dilakukan pengujian kolimator, maka radiograf yang dihasilkan diukur kemudian dianalisis.

Hasil rata-rata dari ketiga pengujian luas bidang $14 \times 18 \mathrm{~cm}$ dengan $F F D 100 \mathrm{~cm}$ diperoleh hasil untuk sumbu horizontal $\left(X_{1}+X_{2}\right)$ sebesar $1,38 \%$ dan untuk sumbu vertikal $\left(Y_{1}+Y_{2}\right)$ sebesar $1,5 \%$. Hasil pengujian pada variasi $F F D 100 \mathrm{~cm}$ tersebut menunjukan penyimpangan terbesar terjadi pada pengujian yang kedua dengan hasil pengujian pada luas bidang $14 \times 18 \mathrm{~cm}$ pada kotak collimator test tool yaitu pada sumbu horizontal $\left(\mathrm{X}_{1}+\mathrm{X}_{2}\right)$ sebesar $1,65 \%$, pada sumbu vertikal $\left(Y_{1}+Y_{2}\right)$ sebesar $2,76 \%$. Penghitungan tersebut didapat dari jumlah pergeseran pada setiap sumbu dibagi FFD yang digunakan yaitu $100 \mathrm{~cm}$ kemudian dikalikan dengan $100 \%$.

Hasil rata-rata dari ketiga pengujian luas bidang $14 \times 18 \mathrm{~cm}$ dengan $F F D 150 \mathrm{~cm}$ diperoleh hasil pada sumbu horizontal $\left(X_{1}+X_{2}\right)$ sebesar $1,73 \%$ dan pada sumbu vertikal $\left(Y_{1}+Y_{2}\right)$ sebesar $1,42 \%$. Hasil pengukuran pada variasi $F F D 150 \mathrm{~cm}$ tersebut menunjukkan penyimpangan terbesar terjadi pada pengujian yang kedua dengan hasil pengujian pada luas bidang $14 \times 18 \mathrm{~cm}$ pada kotak collimator test tool yaitu pada sumbu horizontal $\left(\mathrm{X}_{1}+\mathrm{X}_{2}\right)$ sebesar $1,73 \%$, Pada sumbu vertikal $\left(Y_{1}+Y_{2}\right)$ sebesar $1,73 \%$. Penghitungan tersebut didapat dari jumlah pergeseran pada setiap sumbu dengan FFD yang digunakan yaitu $150 \mathrm{~cm}$ kemudian dikalikan dengan $100 \%$.

Berdasarkan hasil pengolahan data yang telah dilakukan oleh penulis, dapat disimpulkan bahwa hasil pengujian kolimator dengan variasi FFD 100 $\mathrm{cm}$ dan $150 \mathrm{~cm}$ pada sumbu horizontal $\left(X_{1}+X_{2}\right)$ maupaun sumbu vertikal $\left(Y_{1}+Y_{2}\right)$ dengan luas bidang $14 \times 18 \mathrm{~cm}$ menunjukkan ketidak sesuaian atau pergeseran, nilai pergeseran yang terjadi masih dalam batas toleransi ( $\leq 2 \%$ ). Hal ini didapatkan dari hasil penghitungan rata-rata. 


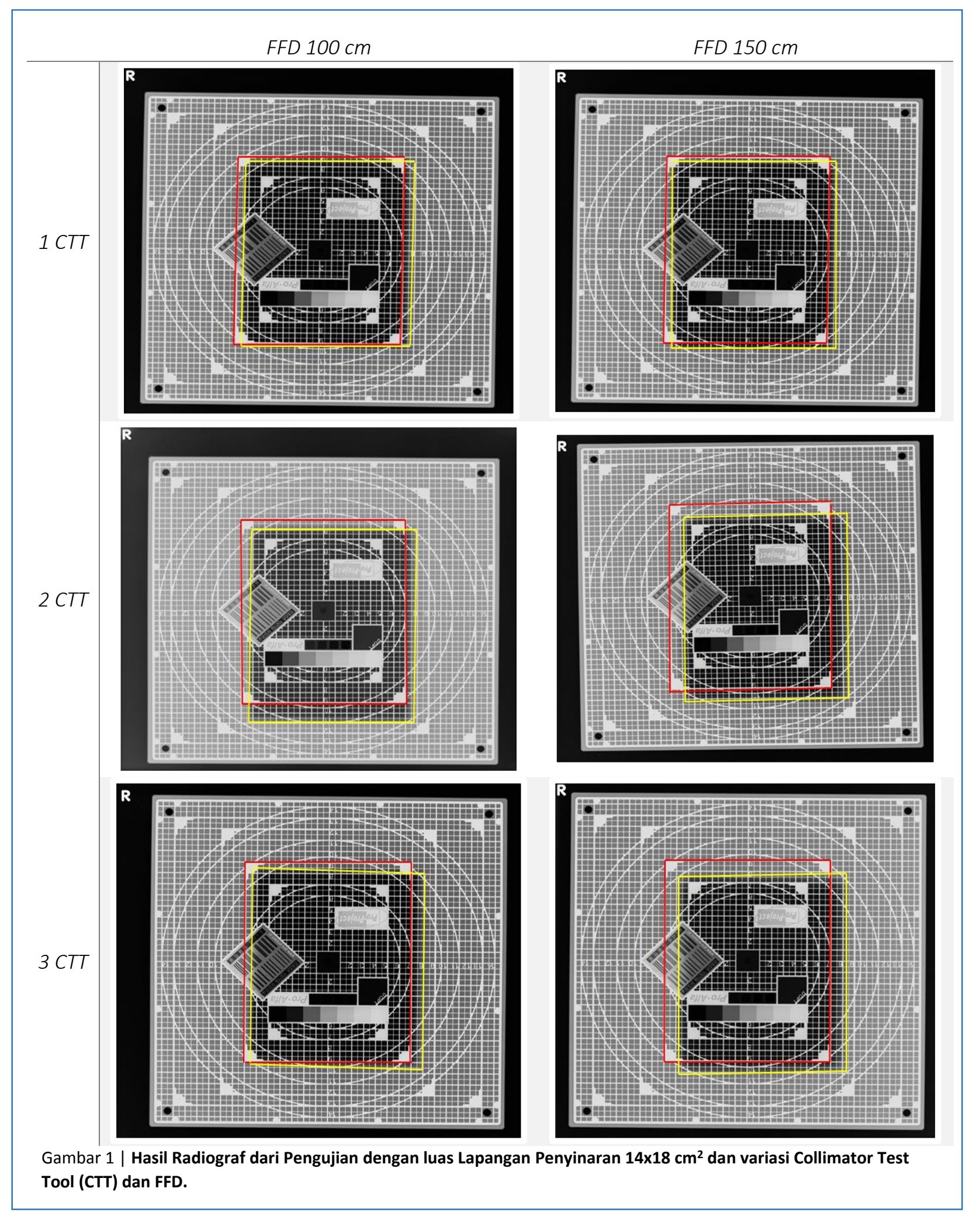

Gambar 1 | Hasil Radiograf dari Pengujian dengan luas Lapangan Penyinaran $14 \times 18 \mathrm{~cm}^{2}$ dan variasi Collimator Test Tool (CTT) dan FFD.

Permasalahan yang sering terjadi pada kolimator yaitu penyimpangan iluminasi, penyimpangan lapangan kolimasi dengan berkas radiasi, dan penyimpangan ketegaklurusan berkas radiasi. Luas lapangan berkas Sinar-X pada pesawat
Sinar-X mobile unit merek Siemens di Instalasi Radiologi RSUD K.R.M.T Wongsonegoro Semarang mengalami pergeseran atau ketidaksesuaian kemungkinan terjadi akibat kondisi shutter pada kolimator kurang baik karena saat dilakukan 
Tabel 1 | Hasil pengujian kesesuaian berkas kolimator dengan variasi FFD $100 \mathrm{~cm}$.

\begin{tabular}{|c|c|c|c|c|}
\hline $\begin{array}{l}\text { Luas } \\
\text { Bidang } \\
14 \times 18 \mathrm{~cm}\end{array}$ & $\begin{array}{c}\mathrm{X} 1 \\
(\mathrm{~cm})\end{array}$ & $\begin{array}{c}\mathrm{X} 2 \\
(\mathrm{~cm})\end{array}$ & $\begin{array}{c}\frac{X 1+X 2}{F F D} \\
(\mathrm{~cm})\end{array}$ & $\begin{array}{c}\text { Hasil } \\
(\%)\end{array}$ \\
\hline 1 & 0,7 & 0,79 & 0,0149 & 1,49 \\
\hline 2 & 0,84 & 0,81 & 0,0165 & 1,65 \\
\hline 3 & 0,5 & 0,52 & 0,0102 & 1,02 \\
\hline Rata-rata & 0,68 & 0,70 & 0,0138 & 1,38 \\
\hline $\begin{array}{l}\text { Luas } \\
\text { Bidang } \\
14 \times 18 \mathrm{~cm}\end{array}$ & $\begin{array}{c}\mathrm{Y} 1 \\
(\mathrm{~cm})\end{array}$ & $\begin{array}{c}\mathrm{Y} 2 \\
(\mathrm{~cm})\end{array}$ & $\begin{array}{c}\frac{Y 1+Y 2}{F F D} \\
(\mathrm{~cm})\end{array}$ & $\begin{array}{c}\text { Hasil } \\
(\%)\end{array}$ \\
\hline 1 & 0,65 & 0,25 & 0,009 & 0,9 \\
\hline 2 & 0,86 & 0,86 & 0,0276 & 2,76 \\
\hline 3 & 0,36 & 0,5 & 0,0086 & 0,86 \\
\hline Rata-rata & 0,62 & 0,88 & 0,015 & 1,5 \\
\hline
\end{tabular}

$\begin{array}{ll}\text { Keterangan: } \\ \mathrm{X} 1 & \text { : Sisi kanan } \\ \mathrm{X} 2 & \text { : Sisi kiri } \\ \mathrm{X} 1+\mathrm{X} 2 & \text { : Penjumlahan sumbu horizontal pada film } \\ \mathrm{Y} 1 & \text { : Sisi atas } \\ \mathrm{Y} 2 & \text { : Sisi bawah } \\ \mathrm{Y} 1+\mathrm{Y} 2 & \text { : Penjumlahan sumbu vertikal pada film }\end{array}$

\begin{tabular}{|c|c|c|c|c|}
\hline $\begin{array}{l}\text { Luas } \\
\text { Bidang } \\
14 \times 18 \mathrm{~cm}\end{array}$ & $\begin{array}{c}\mathrm{X} 1 \\
(\mathrm{~cm})\end{array}$ & $\begin{array}{c}\text { X2 } \\
\text { (cm) }\end{array}$ & $\begin{array}{l}\frac{X 1+X 2}{F F D} \\
(\mathrm{~cm})\end{array}$ & $\begin{array}{c}\text { Hasil } \\
(\%)\end{array}$ \\
\hline 1 & 0,7 & 0,79 & 0,0149 & 1,49 \\
\hline 2 & 0,84 & 0,81 & 0,0165 & 1,65 \\
\hline 3 & 0,5 & 0,52 & 0,0102 & 1,02 \\
\hline Rata-rata & 0,68 & 0,70 & 0,0138 & 1,38 \\
\hline $\begin{array}{l}\text { Luas } \\
\text { Bidang } \\
14 \times 18 \mathrm{~cm}\end{array}$ & $\begin{array}{l}\mathrm{Y} 1 \\
(\mathrm{~cm})\end{array}$ & $\begin{array}{c}\text { Y2 } \\
(\mathrm{cm})\end{array}$ & $\begin{array}{l}\frac{Y 1+Y 2}{F F D} \\
(\mathrm{~cm})\end{array}$ & $\begin{array}{c}\text { Hasil } \\
(\%)\end{array}$ \\
\hline 1 & 0,65 & 0,25 & 0,009 & 0,9 \\
\hline 2 & 0,86 & 0,86 & 0,0276 & 2,76 \\
\hline 3 & 0,36 & 0,5 & 0,0086 & 0,86 \\
\hline Rata-rata & 0,62 & 0,88 & 0,015 & 1,5 \\
\hline
\end{tabular}

Keterangan: sama dengan keterangan pada tabel 1.

penutupan atau saat mengatur luas lapangan terjadi ketidaksejajaran pada kolimator atau tidak simetris antara kanan dan kiri.

\section{Kesimpulan}

Berdasarkan hasil pengujian kolimator dengan metode Collimator Test Tool pada pesawat Sinar-X mobile unit merek Siemens di Instalasi Radiologi RSUD K.R.M.T Wongsonegoro Semarang dapat disimpulkan bahwa hasil pengujian kolimator dengan variasi $F F D 100 \mathrm{~cm}$ dan $150 \mathrm{~cm}$ pada luas bidang $14 \times 18 \mathrm{~cm}$ mengalami ketidaksesuaian atau pergeseran. Hal ini didapatkan dari hasil penghitungan rata-ratapada variasi $F F D 100 \mathrm{~cm}$ sumbu horizontal $\left(X_{1}+X_{2}\right)$ sebesar $1,38 \%$, pada sumbu vertikal $\left(Y_{1}+Y_{2}\right)$ sebesar $1,5 \%$. Pada variasi FFD 150 diperoleh rata-rata pada sumbu horizontal $\left(X_{1}+X_{2}\right)$ sebesar $1,73 \%$, pada sumbu vertikal $\left(Y_{1}+Y_{2}\right)$ sebesar $1,42 \%$, akan tetapi pergeseran yang terjadi masih dalam batas toleransi yang ditetapkan oleh KEMENKES No. 1250 tahun 2009 yaitu $\leq 2 \%$ dari FFD yang digunakan.

Hal ini menunjukkan bahwa perlu dilakukan perbaikan kolimator khususnya pada bagian shutter pada pesawat Sinar-X mobile unit merek Siemens di Instalasi Radiologi RSUD K.R.M.T Wongsonegoro Semarang. Sehingga dapat mengurangi kemungkinan pengulangan foto karena kondisi shutter yang kurang baik dan gambaran radiograf terpotong akibat dari berkas Sinar- $X$ yang mengalami pergeseran.

Selain itu perlu dilakukan pengujian secara berkala pada pesawat Sinar-X mobile unit merek Siemens di Instalasi Radiologi RSUD K.R.M.T Wongsonegoro Semarang yaitu satu bulan sekali sesuai dengan peraturan yang ada (KEMENKES No. 1250 Tahun 2009 Tentang Pedoman Kendali Mutu Peralatan Radiodiagnostik).

\section{Bibliografi}

1. BAPETEN, Peraturan Kepala Nomor 9 Tahun 2011 Tentang Uji Kesesuaian pesawat Sinar-X Radiologi Diagnostik dan Intervensional.

2. KEMENKES RI NO. 1250/MENKES/SK/II/2009, Pedoman Kendali Mutu (Quality Control) Peralatan Radiodiagnostik, Jakarta.

3. Papp, Jefrey. 2011. Quality Management In The Imaging Sciences, Third Edition, USA: Mosby Elsevier.

4. Puspitasari, Oktavia. 2010. Fisika Radiasi. Universitas Baiturrahman : Padang. 